\title{
ERRATUM
}

\section{Ablative neurosurgery for mental disorders: is there still a role in the 21st century? A personal perspective}

TO THE READERSHIP: I recently was made aware of an error in my paper (Eljamel MS: Ablative neurosurgery for mental disorders: is there still a role in the 21st century? A personal perspective. Neurosurg Focus 25(1):E4, 2008).

While preparing my paper I selected an MR image (Fig. 5) from a collection of postoperative images that I believed all belonged to my institution at the time, Ninewells Hospital and Medical School in Dundee, Scotland, UK. I thought that the image showed a coronal T2-weighted MR image from a patient who had undergone bilateral anterior capsulotomy (BACA) there 12 months earlier. Recently, I discovered that the MR image was actually obtained 6 months after BACA in a patient treated by Brian A. Simpson, MD, FRCS, in Cardiff, UK.

Despite this error, the MRI from Dr. Simpson's collection serves as a good example of a follow-up image after BACA, and with Dr. Simpson's permission I have decided to keep it in the paper. I have corrected the figure legend to more accurately state the timing of postoperative imaging and to acknowledge Dr. Simpson. The figure and the new legend are shown here.

I thank Dr. Simpson for graciously sharing his figure.

M. Sam Eljamel, MD, FRCS(Ire), FRCS(Edin), FRCS(SN)

High Tech Neuro \& Micro Surgery Ltd., Edinburgh, United Kingdom

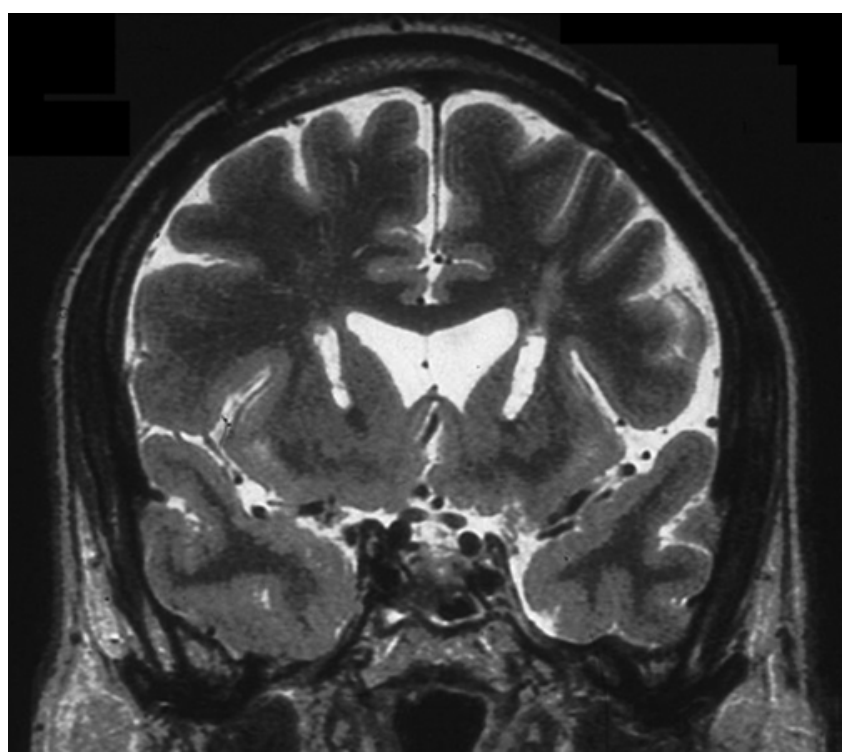

FIG. 5. Follow-up coronal T2-weighted MR image obtained in a patient who underwent BACA; in this case the image was obtained 6 months postoperatively. From the collection of Brian A. Simpson, MD, FRCS; used with permission.

INCLUDE WHEN CITING

DOI: 10.3171/2018.1.FOCUS0814a.

CAANS 2018, except where prohibited by US copyright law 